\title{
Spatial and color working memory in patients with lateral prefrontal cortex lesions
}

\author{
JULIANA V. BALDO \\ Veterans Administration Northern California Health Care System, Martinez, California \\ and \\ ARTHUR P. SHIMAMURA \\ University of California, Berkeley, Califormia
}

\begin{abstract}
Lateral prefrontal cortex (LPFC) has previously been associated with both attention and working memory. To study both of these mechanisms, patients with LPFC lesions and age-matched controls were tested on working memory tasks that included an interference condition. On a spatial working memory task, patients were impaired overall relative to controls in both no-interference and interference conditions. There was also a significant correlation between patients' performance and the extent of damage to Area 46. Participants were also tested on a color working memory paradigm, in which they had to remember an object's color, rather than location. LPFC patients were disproportionately impaired in the interference condition of this experiment-namely, when they had to perform an interference task during the delay period of the color working memory task. These results are discussed with respect to previous animal and human studies of attention and working memory.
\end{abstract}

Recent neuropsychological and neuroimaging findings have suggested that human lateral prefrontal cortex (LPFC) contributes significantly to short-term or working memory (Awh et al., 1996; Chao \& Knight, 1996; Cohen et al., 1997; D'Esposito et al., 1995; Fiez et al., 1996; Freedman \& Oscar-Berman, 1986; Jonides et al., 1993; Ptito, Crane, Leonard, Amsel, \& Caramanos, 1995). Working memory refers to processes involved in the selection and manipulation of memory representations (see Baddeley, 1986; Fuster, 1989; Goldman-Rakic, 1987). It is also used to denote memories that are currently active or maintained in short-term memory. In neuropsychological studies, patients with LPFC lesions exhibit impairment on tasks that involve selecting, maintaining, or controlling items in working memory (for review, see Petrides, 1998, Shimamura, 1995, and Smith \& Jonides, 1999). Similarly, neuroimaging studies have indicated increased activation in LPFC (e.g., Brodmann's Areas 9, 10, and 46) on tasks that involve the ability to hold information across trials or manipulate information in working memory (e.g., Cohen et al., 1997; D'Esposito et al., 1995; Jonides et al., 1993; McCarthy et al., 1994; Petrides, Alivisatos, Evans, \& Meyer, 1993).

Empirical investigations using animal models to assess the role of prefrontal cortex in working memory have a

This research was supported by National Institutes of Health Grants MH48757 and NS17778 and a National Science Foundation Pre-Doctoral Fellowship. The authors thank William Prinzmetal for his assistance in this study. The authors also thank all the participants and their families for their involvement in this research. Correspondence should be addressed to J. V. Baldo, VA Northern California Health Care System, 150 Muir Rd., 126 s, Martinez, CA 94553 (e-mail: juliana@socrates.berkeley.edu). much longer history. In early lesion studies, Jacobsen (1936) showed that prefrontal cortex is critically involved in the delayed-response task, a task in which a monkey must remember which of two objects or locations was recently rewarded. Impairment on this task has served as a benchmark feature of prefrontal lesions (Blake, Meyer, \& Meyer, 1966; Fuster \& Alexander, 1971; Goldman \& Rosvold, 1970; Mishkin \& Pribram, 1956). Moreover, neurobiological analyses of the delayed-response task have provided the foundation for elegant physiological and anatomical findings, such as those by Goldman-Rakic, Fuster, Miller and others (see Fuster, 1989; GoldmanRakic, 1998; Miller, Erickson, \& Desimone, 1996). For example, Funahashi, Bruce, and Goldman-Rakic (1993) showed that monkeys with prefrontal lesions involving the region surrounding the sulcus principalis exhibit deficits in spatial working memory that correspond to specific locations in the visual field. Such deficits have been termed memory scotomas and suggest that there is some specificity in the LPFC in terms of spatial representations. The nature of these memory representations is rather complex (see Rainer, Asaad, \& Miller, 1998) and likely involves the participation of posterior cortical regions that represent spatial knowledge (Rao, Rainer, \& Miller, 1997; Wilson, Scalaidhe, \& Goldman-Rakic, 1993).

Another interpretation of prefrontal function has focused on attentional demands during the encoding of stimuli. That is, prefrontal cortex is presumed to be involved in selecting relevant stimulus features and filtering irrelevant features. Jacobsen himself noted that monkeys with LPFC lesions were highly distractible in their everyday behavior (Jacobsen, 1936). Such observations led others to suggest that impairments on delayed-response tasks are 
due primarily to a deficit of attention and not memory (Bartus \& Levere, 1977; Malmo, 1942). Indeed, findings from monkeys with LPFC lesions have supported this stimulus-filtering hypothesis by demonstrating disproportionate impairment on delayed-response performance in the presence of visual distraction during the delay period (Bartus \& Levere, 1977; Malmo, 1942).

Problems in stimulus filtering have been demonstrated in patients with frontal lobe lesions who exhibit particular memory impairment under conditions of high distraction (see Shimamura, 1995). For example, Chao and Knight (1996) used an auditory short-term memory task in which participants were asked to remember a sound (e.g., a dog bark) after a delay period. On some trials, participants were presented distracting irrelevant tones during the delay. Patients with LPFC lesions were disproportionately impaired across delays when interference was present, relative to normal controls and patients with temporoparietal lesions.

In the present study, working memory was assessed in patients with LPFC lesions and control participants. In Experiments $1 \mathrm{~A}$ and $1 \mathrm{~B}$, participants performed a spatial working memory task modeled after those used in monkey studies (e.g., Funahashi et al., 1993). In Experiment 2, performance on a color working memory task was assessed in which participants were required to remember the color of a target stimulus. In both the spatial and the color working memory tasks, performance was assessed in two delay conditions- - with and without interference. These experiments addressed the degree to which patients with LPFC exhibit working memory deficits on different kinds of working memory tasks (spatial vs. color) and under high and low levels of interference.

\section{EXPERIMENT 1A}

Spatial working memory deficits have been associated with LPFC damage in primate models. One type of working memory paradigm used in monkey studies, known as the oculomotor task, requires monkeys to remember the spatial location of a target presented in one of several locations on a screen (Goldman-Rakic, 1987). Monkeys are taught to maintain central fixation until after the delay, at which time they attempt to make a saccade to the original target location. Experiments $1 \mathrm{~A}$ and $1 \mathrm{~B}$ used an analogous design, modified so as to make it appropriate as well as sufficiently difficult for human participants. Instead of a saccadic response, participants indicated the spatial location by using a mouse device to indicate the location on the screen. In Experiment 1A, delays of 0, 3, and $9 \mathrm{sec}$ were used; in Experiment 1B, delays of 0, 9, and $20 \mathrm{sec}$ were used.

\section{Methods}

Participants. Twelve patients with unilateral prefrontal cortex lesions ( 3 women and 9 men) were tested in this experiment. Of these patients, 7 had left-hemisphere lesions and 5 had right-hemisphere lesions. An additional patient (L.S.) was initially tested but performed extremely poorly on the spatial working memory task (with error rates of greater than 2 standard deviations from patients' mean performance) and, therefore, was excluded. In 10 of the patients, lesions were due to a single infarction of the precentral branch of the middle cerebral artery. In the other 2 patients, lesions were due to surgical resection for a cyst and arteriovenous malformation (see Table 1 for clinical information). Lesion sites were identified by computed tomography (CT) or magnetic resonance (MR) images (see Figure 1 for lesion reconstructions). Patients with multiple lesions or lesions extending significantly into other regions were excluded. The average lesion volume as determined by CT/MR reconstruction was $40.4 \mathrm{cc}(S D=28.7)$, and time since cerebrovascular accident (CVA) was 9.4 years $(S D=4.7)$. Five of the patients had some degree of nonfluent aphasia, but all were able to comply with the experimenter's instructions.

Ten healthy participants ( 3 women and 7 men), recruited from the community, participated as a normal control group. Both patient and control groups were screened for a history of psychiatric disorders, dementia, drug abuse, and head injury. All participants were right-handed. Patients and controls did not differ in terms of age $(M=64.7$ years, $S D=13.3$, and $M=65.0$ years, $S D=6.2$, respectively) $[F(1,20)=.01, p>.9]$ or years of education $(M=13.8$ years, $S D=1.9$, and $M=14.4$ years, $S D=2.3$, respectively) $[F(1,20)=$ $.38, p>.5]$. Testing was completed at the Veterans Administration Northern California Health Care System (Martinez, CA). All participants signed consent forms prior to participating in the experiment.

Design and Materials. The design of Experiment $1 \mathrm{~A}$ consisted of three within-subjects variables: delay $(0,3$, or $9 \mathrm{sec})$, visual field (right or left), and task condition (no interference or interference). There was one between-subjects variable: participant group (patient or control). The participants were presented a total of four test blocks, each consisting of 48 spatial memory trials. On two of these blocks, the participants performed the interference task during the delay period; on the other two blocks, the participants stared passively at this display but did not respond to it. Half of the patients and controls completed the interference condition first, and half completed the no-interference condition first. The delay and visual field variables were randomly mixed within blocks. On half of the trials, the target appeared on the left half of the screen and on the other half, the target appeared on the right side of the screen. The three delay conditions were also randomly interspersed with 16 trials of each delay per block.

Procedure. The participants were tested individually in a testing room with minimal background noise. The task was presented on a 12-in. Apple monitor connected to a Macintosh computer. The participants were seated approximately $60 \mathrm{~cm}$ from the computer monitor. Before each task condition, the experimenter demonstrated how to perform the task on two or three trials (or more if the participant did not seem to understand). The participants then practiced for 10 trials, during which the experimenter gave feedback. Following practice, the participants performed two blocks of trials. After a small break, this procedure was repeated for the other task condition. All participants used the right hand to perform the task, except for 2 patients with hemiplegia who used the nondominant, left hand.

The sequence of events in a trial is shown schematically in Figure $2 \mathrm{~A}$. On a given trial, a fixation stimulus (a square subtending a visual angle of $0.5^{\circ}$ ) appeared at the center of the monitor. To initiate a trial, the participants moved a cursor (a cross subtending a visual angle of $0.6^{\circ}$ ) to the fixation stimulus and clicked on the mouse device. Immediately following the mouse click, the target stimulus appeared, with an exposure duration of $100 \mathrm{msec}$. The target stimulus consisted of a black dot (a circle subtending a visual angle of $0.6^{\circ}$ ), which could appear anywhere within an annulus defined by 


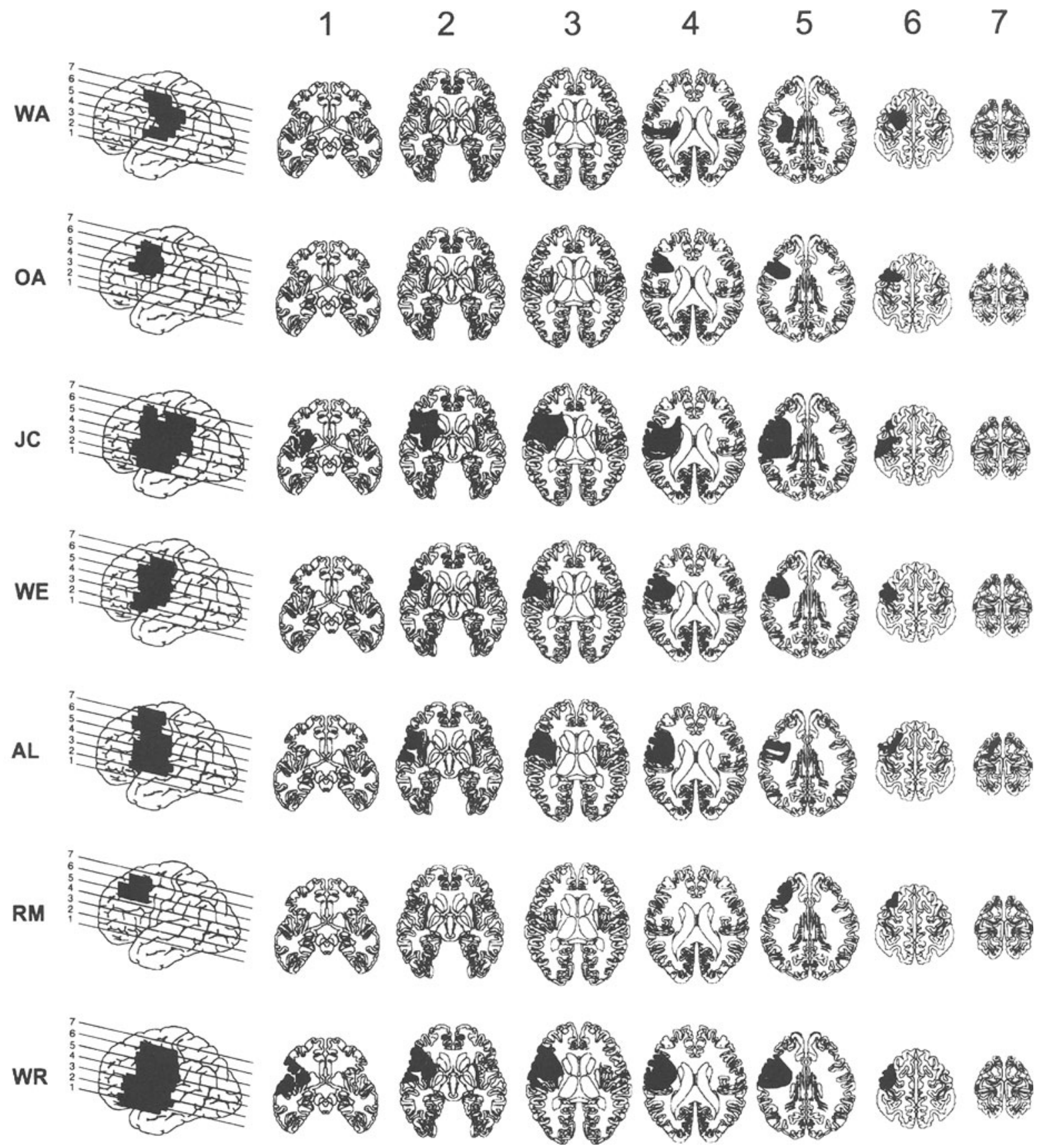

Figure 1. Patients' lesions based on CT and MRI reconstructions. Slices 1-7 are shown to the right of the lesion image for each patient.

an inner radius of $6.6^{\circ}$ and an outer radius of $8.1^{\circ}$. To define the border between left and right visual field targets, there was an area $\left(1.9^{\circ}\right.$ wide) directly above and below the central fixation within which targets could not appear.

During the delay period, a series of digits were displayed just below the fixation stimulus. The participants were instructed to keep the cursor on the fixation stimulus until the digits were no longer presented $(3$ or $9 \mathrm{sec})$. Thus, the time during the presentation of the digits defined the delay period. For the 0 -sec delay, no digits were presented, and the participants made their responses immediately after the target stimulus was presented.
The presentation of the digits was used in the task manipulation. In the interference condition, the participants were instructed to monitor the digits and click on the mouse every time they saw a " 0 ." Digits appeared at the rate of approximately 1 per $170 \mathrm{msec}$. The participants had approximately $800 \mathrm{msec}$ to click the mouse for each " 0 "; if they clicked after this period, it was counted as a miss. Hits (correct identification of a "0"), false alarms (responses to digits other than " 0 "), and misses (no response to a " 0 ") were recorded. The participants were given auditory feedback on the digit task in the form of a high-pitched beep for hits and a low-pitched beep for false alarms and misses. In the no-interference condition, the partic- 

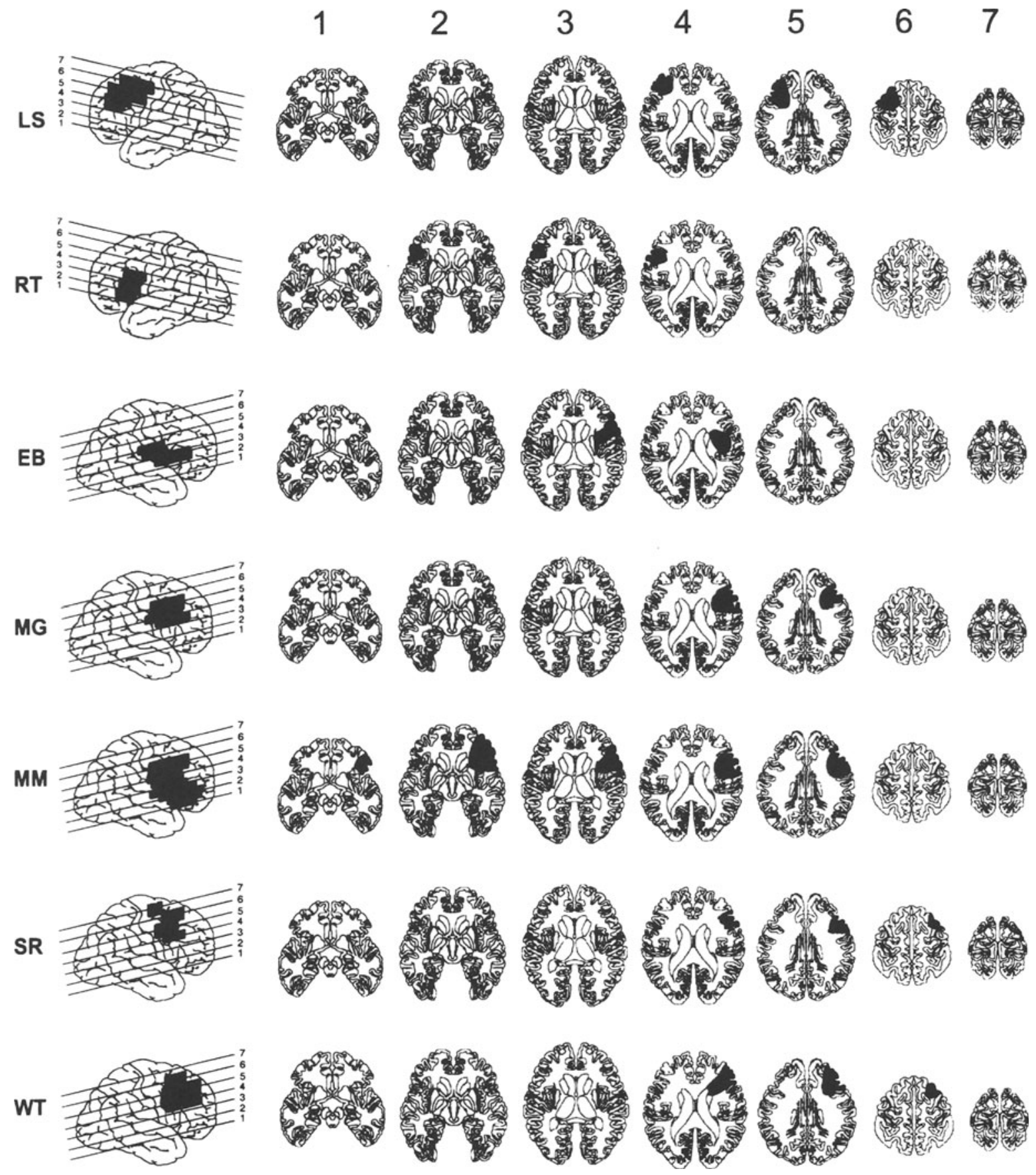

Figure 1 (cont'd). Patients' lesions based on CT and MRI reconstructions. Slices 1-7 are shown to the right of the lesion image for each patient.

ipants were not required to monitor or respond to the digits. In this condition, low-pitched beeps were presented intermittently as the participants were not responding. This auditory stimulus was presented to equate for possibly distracting auditory stimulation across the interference and no-interference conditions.

Responses to indicate the spatial location of targets were not timed. However, the participants made their responses immediately after the delay. The dependent variable was spatial error, defined as the distance in number of pixels from the actual target location to the remembered dot location $(72$ pixels $=2.5 \mathrm{~cm})$.

\section{Results and Discussion}

Patients versus elderly controls. Spatial error data were analyzed in a $3 \times 2 \times 2 \times 2$ mixed analysis of variance (ANOVA), with delay $(0,3$, or $9 \mathrm{sec})$, visual field (right 
Table 1

Neuropsychological Characterization of Participants

\begin{tabular}{|c|c|c|c|c|c|c|c|c|c|c|}
\hline $\begin{array}{l}\text { Frontal } \\
\text { Patients }\end{array}$ & Gender & $\begin{array}{c}\text { Lesion } \\
\text { (side) }\end{array}$ & $\begin{array}{c}\text { Volume } \\
\text { (cc) }\end{array}$ & $\begin{array}{c}\% \text { Area } 46 \\
\text { Affected }\end{array}$ & Age & $\begin{array}{l}\text { Onset } \\
\text { (year) }\end{array}$ & $\begin{array}{c}\text { Lesion } \\
\text { Etiology }\end{array}$ & $\begin{array}{c}\text { Experiments } \\
\text { Completed }\end{array}$ & $\begin{array}{c}\text { Education } \\
\text { (years) }\end{array}$ & $\begin{array}{c}\text { WAIS-R } \\
\text { PIQ }\end{array}$ \\
\hline R.M. & $\mathbf{M}$ & $\mathrm{L}$ & 10.3 & 0.0 & 69 & 1989 & Stroke & $1 \mathrm{~A}, 2$ & 12 & 95 \\
\hline A.L. & $\mathrm{F}$ & $\mathrm{L}$ & 51.2 & 0.0 & 65 & 1980 & Stroke & $1 \mathrm{~A}, 1 \mathrm{~B}, 2$ & 13 & 99 \\
\hline O.A. & M & $\mathrm{L}$ & 17.5 & 0.0 & 62 & 1984 & Stroke & $1 \mathrm{~A}, 1 \mathrm{~B}, 2$ & 14 & 134 \\
\hline W.A. & $\mathrm{F}$ & L & 26.2 & - & 74 & 1986 & Stroke & 1B & 14 & 132 \\
\hline R.T. & $\mathrm{M}$ & $\mathrm{L}$ & 38.7 & 53.5 & 81 & 1981 & Stroke & $1 \mathrm{~A}, 1 \mathrm{~B}, 2$ & 16 & 89 \\
\hline W.R. & M & $\mathrm{L}$ & 91.6 & 25.2 & 53 & 1990 & Stroke & $1 \mathrm{~A}, 1 \mathrm{~B}, 2$ & 15 & 63 \\
\hline W.E. & M & $\mathrm{L}$ & 41.1 & 1.1 & 67 & 1995 & Stroke & $1 \mathrm{~A}, 1 \mathrm{~B}, 2$ & 14 & 95 \\
\hline J.C. & $\mathbf{M}$ & $\mathrm{L}$ & 102.6 & 5.8 & 72 & 1987 & Stroke & $1 \mathrm{~A}, 2$ & 16 & 103 \\
\hline L.S. & $F$ & $\mathrm{~L}$ & 27.9 & 16.0 & 67 & 1981 & Meningioma & 2 & 16 & - \\
\hline E.B. & F & $\mathrm{R}$ & 17.3 & 10.4 & 77 & 1983 & Stroke & $1 \mathrm{~A}, 1 \mathrm{~B}, 2$ & 12 & 114 \\
\hline M.M. & M & $\mathrm{R}$ & 51.2 & 45.6 & 69 & 1984 & Stroke & $1 \mathrm{~A}$ & 12 & 99 \\
\hline S.R. & F & $\mathrm{R}$ & 12.9 & 0.0 & 76 & 1995 & Stroke & $1 \mathrm{~A}, 1 \mathrm{~B}, 2$ & 12 & 93 \\
\hline W.T. & $\mathbf{M}$ & $\mathrm{R}$ & 25.9 & 4.2 & 52 & 1988 & Cyst removal & $1 \mathrm{~A}, 1 \mathrm{~B}$ & 18 & - \\
\hline M.G. & $\mathbf{M}$ & $\mathrm{R}$ & 24.5 & 0.0 & 33 & 1984 & AVM removal & $1 \mathrm{~A}, 1 \mathrm{~B}, 2$ & 12 & - \\
\hline \multicolumn{11}{|c|}{ Means } \\
\hline Frontal & $9 \mathrm{M}, 5 \mathrm{~F}$ & $9 \mathrm{~L}, 5 \mathrm{R}$ & 38.5 & 12.2 & 65.5 & 1987 & - & - & 14.0 & 101.4 \\
\hline Control & $7 \mathrm{M}, 3 \mathrm{~F}$ & - & - & & 65.9 & - & - & - & 14.6 & - \\
\hline
\end{tabular}

Note-WAIS-R PIQ = Wechsler Adult Intelligence Scale-Revised Performance scale. — represents data that were not available or not applicable.

or left), task condition (interference or no-interference), and group (patient or control) as variables. Task order (interference or no interference task) was included in a preliminary analysis as a factor. There was no main effect of task order $[F(1,18)=1.61, p=.22]$, but there was a significant block order $\times$ participant group interaction $[F(1,18)=4.88, p<.05]$, since controls performed comparably in the two block orders, but patients doing the interference task condition first outperformed patients who did it second. However, there were no other significant interactions with block order; thus, this factor was not included in the analysis presented here for purposes of simplification.

Spatial error as a function of delay and interference condition are displayed in Figure 3A for for LPFC patients and controls. As predicted, there was a significant
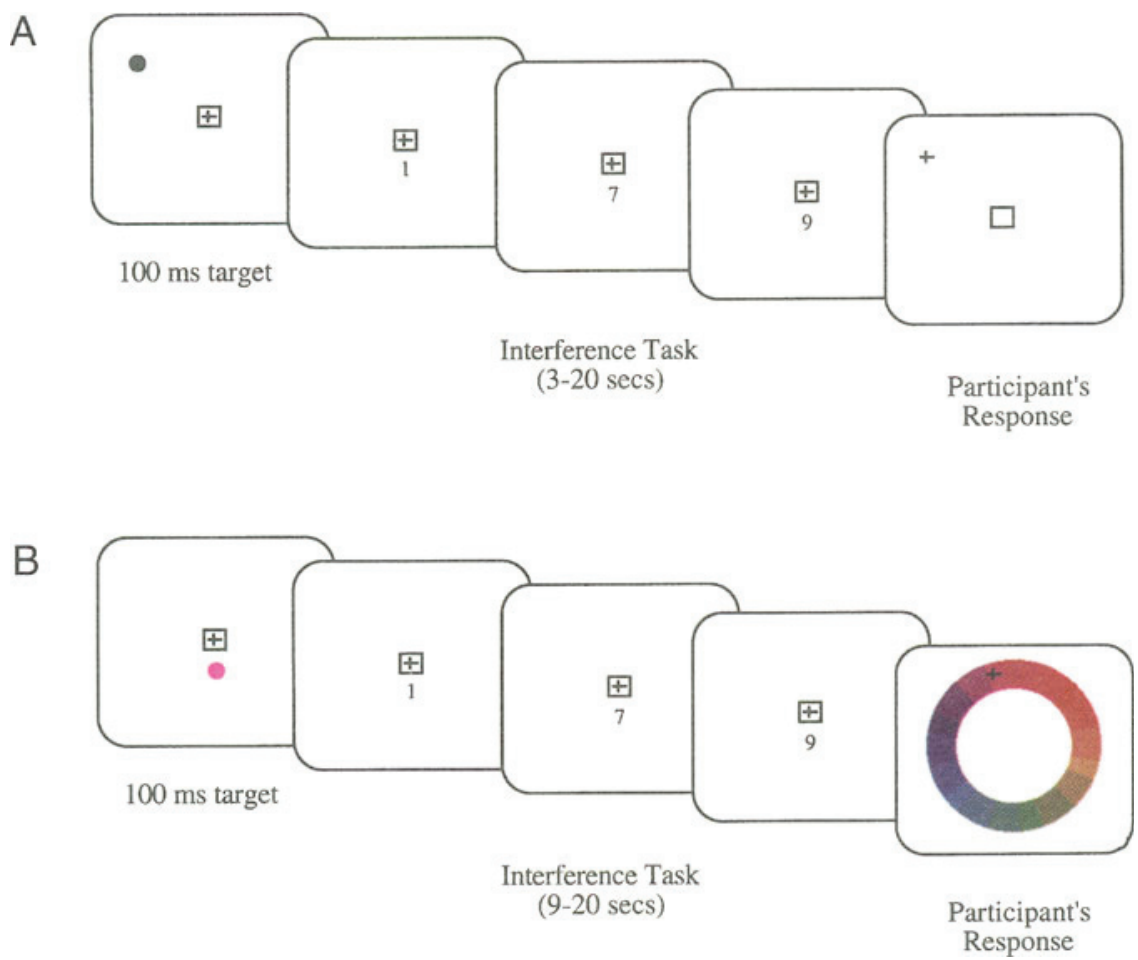

Figure 2. Schematic illustration of the sequence of events in a representative trial in Experiments 1 (A) and 2 (B). 
A

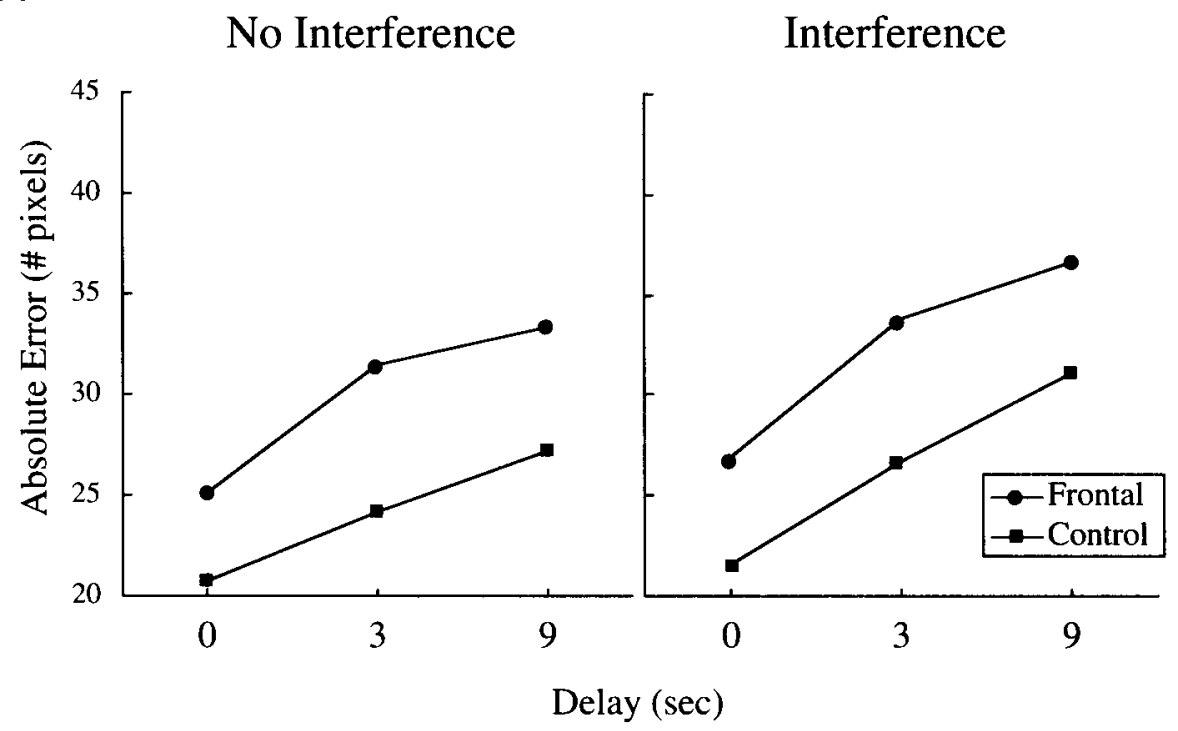

B

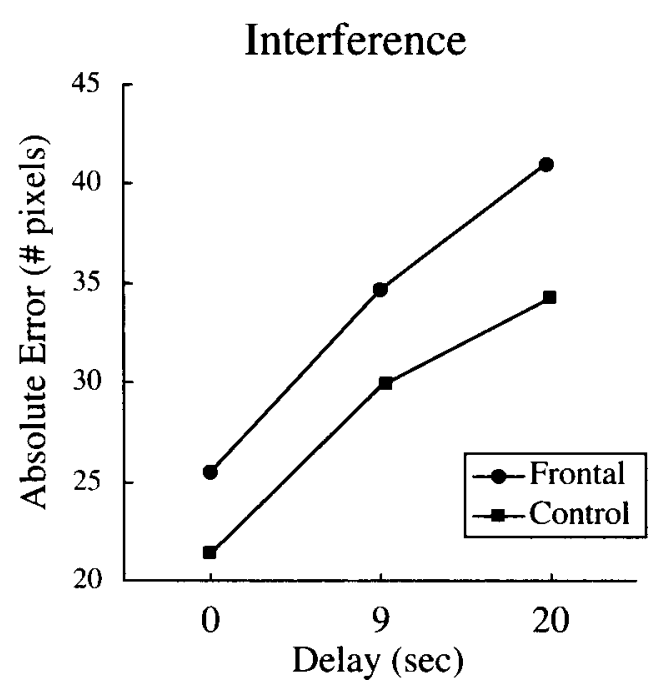

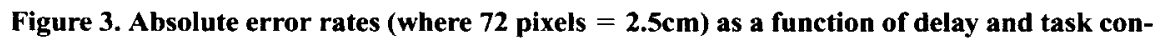
dition for frontal patients and controls in Experiments $1 \mathrm{~A}(\mathrm{~A})$ and $1 \mathrm{~B}$ (B).

main effect of group $[F(1,20)=8.64, p<.01]$, since patients performed worse overall on the spatial working memory task, relative to controls. There was also a main effect of delay $[F(2,40)=66.62, p<.0001]$, since all participants' performance was worse at longer delays. There was also a main effect of task condition $[F(1,20)=$ $13.26, p<.01]$. This reflected the fact that both patients and controls performed more poorly with interference than without interference.

There was a significant interaction of target location $\times$ task condition $[F(1,20)=5.51, p<.05]$. This interaction reflected the fact that the participants' error rates were comparable in the no-interference and interference conditions when targets appeared on the left side of the screen, but error rates were much greater in the interference task condition when targets appeared on the right side of the screen. This interaction may represent a hemispheric effect such that the interference task competes for resources within the left hemisphere, and, thus, maintaining a working memory representation in this hemisphere (i.e., right visual field targets) is compromised.

There were no other significant interactions. The delay $\times$ participant group interaction did not approach significance $[F(2,40)=1.25, p=.30]$, since the pattern of error rates in patients and controls was similar across the three delays. The task condition $\times$ participant group interaction was also not significant $[F(1,20)=0.003, p=.95]$, since there was a comparable decrement in performance 
for patients and controls in the interference task condition relative to the single-task condition.

Right- versus left-hemisphere patients. To determine whether the pattern of responses was different for right- versus left-hemisphere patients, a separate analysis was performed on the patient group alone. The patient data were subjected to a $3 \times 2 \times 2 \times 2$ mixed ANOVA, with delay $(0,3$, or $9 \mathrm{sec})$, target location (right or left), task condition (no-interference or interference task), and lesion side (right or left) as variables. As in the overall analysis, there was a main effect of delay $[F(2,20)=37.37$, $p<.0001]$ and a main effect of task condition $[F(1,10)=$ $5.42, p<.05]$. However, there were no other effects or interactions. That is, right- and left-hemisphere patients did not differ in their performance overall $[F(1,10)=0.14$, $p=.71]$, and they did not differ in their patterns of responding across the three delays $[F(2,20)=0.46, p=$ $.64]$. There was also no interaction of target location and lesion side $[F(1,10)=1.48, p=.25]$.

Interference task. Responses on the interference task were analyzed to compare patients' and controls' performance on this secondary task across the two delay conditions ( 3 and $9 \mathrm{sec})$. There was a main effect of group $[F(1,20)=4.76, p<.05]$, since patients made fewer hits than did controls overall. The mean hit rate (percentage of targets responded to $)$ was $75.3 \%(S D=20.4)$ in patients and $90.0 \%(S D=7.7)$ in controls. Neither the main effect of delay nor the interaction of delay $\times$ group was significant. The mean false-alarm rate (percentage of nontargets responded to $)$ was $2.2 \%(S D=2.3)$ in patients and $0.6 \%(S D=0.4)$ in controls, which did differ $[F(1,20)=4.54, p<.05]$.

A separate analysis of the interference data was done using $d^{\prime}$ scores, which takes into consideration both hit and false-alarm rates. Patients and controls differed significantly in terms of $d^{\prime}$ scores $[F(1,20)=8.16, p<.01]$. Mean $d^{\prime}$ in patients was $3.10(S D=0.84)$ and in controls was $4.00(S D=0.59)$, suggesting that patients were impaired overall on the interference task.

Although patients had a lower mean hit rate than controls, this pattern did not appear to be due to a strategy of ignoring the interference task in order to focus on the primary task, because patients also had higher falsealarm rates. Patients were simply much poorer at the interference task than were controls. It is possible that this impaired performance was due to the fact that the spatial working memory taxed the patients' resources to a great extent. We did not have the opportunity to separately assess performance on the two tasks (spatial working memory and interference task).

Correlations with lesion volume and chronicity. A correlational analysis was conducted to investigate the relationship between performance on the spatial working memory task and the extent of damage to Area 46 . The patients tested had varying degrees of injury, ranging from $0 \%$ to $54 \%$ of Area 46 affected (based on reconstructions of the lesions using neuroimaging software; see Table 1). The performance measure was the average absolute error across all conditions of the experiment. The correlation between percentage of Area 46 damaged and performance was significant $(R=.62, p<.05)$ and reflected the fact that patients with more Area 46 damage performed worse on the task. Importantly, this correlation was not confounded by lesion volume, which did not correlate significantly with performance $(R=.04, p>.91)$. There was also no correlation between performance and time since neurological insult $(R=.19, p>.55)$.

\section{EXPERIMENT 1B}

In Experiment 1B, an attempt was made to maximally tax working memory on the spatial memory task. LPFC patients and controls were assessed using a longer delay period $(20 \mathrm{sec})$ in the interference condition. Thus, while performing the interference task, participants were required to maintain the spatial location of the target stimulus for a considerably longer time than in Experiment $1 \mathrm{~A}$. By taxing working memory demands (and, as a result, frontal lobe function), we sought to maximize the effects of delay.

\section{Method}

Participants. In Experiment 1B, 10 patients with frontal lobe lesions were assessed ( 6 left-hemisphere patients and 4 righthemisphere patients), as well as the same 10 control participants as in Experiment IA (see Table 1). In this patient group, average lesion volume was $34.7 \mathrm{cc}(S D=22.1)$, and time since CVA was 9.3 years $(S D=5.1)$. Again, patients and controls did not differ in terms of age $(M=64.0$ years, $S D=14.7$, and $M=65.0$ years, $S D=6.2$, respectively) $[F(1,18)=.04, p>.8]$ or education $(M=14.0$ years, $S D=1.8$, and $M=14.4$ years, $S D=2.3$, respectively) $[F(1,18)=$ $.18, p>.6]$.

Design and Materials. The design and materials used in Experiment $1 B$ were the same as those used in the interference condition of Experiment 1A, except that the delays were 0, 9, and $20 \mathrm{sec}$ Because this experiment sought to characterize group effects under high working memory demands (i.e., long delays with interference), performance with no interference was not assessed.

\section{Results and Discussion}

Data were analyzed in a $3 \times 2 \times 2$ mixed ANOVA, with delay $(0,9$, or $20 \mathrm{sec})$, target location (right or left), and group (patient or control) as independent variables. As shown in Figure 3B, the pattern of error rates was similar to that in Experiment 1A. Again, there was a main effect of participant group $[F(1,18)=5.30, p<.05]$, since patients performed worse overall relative to controls. There was also a main effect of delay $[F(2,36)=77.55$, $\mathrm{p}<.0001]$, since all participants performed worse as the delay increased. However, there were no significant interactions in this analysis. Thus, lengthening the delay did not alter the results observed in Experiment $1 \mathrm{~A}-$ namely, there was still no interaction of participant group $\times$ delay $[F(2,36)=0.84, p=.44]$. Moreover, separate 
analyses revealed no significant effect of hemisphere nor any evidence of a selective impairment in patients' contralesional visual field.

For the interference task, $d^{\prime}$ scores were calculated and analyzed. Patients again had lower average $d^{\prime}$ scores $(M=2.52, S D=0.80)$ than controls $(M=3.80, S D=$ $0.33)[F(1,18)=22.28, p<.001]$, suggesting impaired performance on the interference task overall.

Summary. Across both Experiments $1 \mathrm{~A}$ and 1B, patients with LPFC were impaired on a spatial working memory task, relative to controls. Patients' performance was impaired even at a 0 -sec delay condition, which suggests that their impairment was due to a deficit in stimulus encoding (see General Discussion section). It is possible that a working memory deficit was masked by this larger encoding deficit. Patients and controls showed a comparable cost in performance when the spatial working memory task was coupled with an interference task during the delay period. Interestingly, there was a correlation between the extent of damage to Area 46 (a subset of lateral prefrontal cortex) and patients' performance on the spatial working memory task. There was no evidence of any hemispheric effects: Patients with right and left lesions performed comparably, and there was no evidence of a deficit in patients' contralesional visual field.

\section{EXPERIMENT 2}

In Experiment 2, performance on a nonspatial color working memory task was assessed. Both human and animal studies have suggested that spatial and object working memory are mediated by separate regions or hemispheres of LPFC (McCarthy et al., 1996; Smith et al., 1995; Wilson et al., 1993; but see Rao et al., 1997). Thus, it was of interest to assess working memory performance when it was necessary to select and maintain color information. In this experiment, participants were required to remember the color, rather than the location, of a dot that was flashed in the center of the screen. In order to make the task comparable to the spatial location task used in Experiment 1, participants responded by clicking on the remembered color on a spectrum made up of 254 colors (see Figure 2B). As in Experiment 1A, participants performed the color working memory task with and without an additional interference task.

\section{Method}

Participants. Eleven patients with unilateral frontal lobe lesions ( 4 women and 7 men) participated in Experiment 2. Ten of these patients had participated in Experiment 1 (see Table 1). In 9 of the patients, lesions were due to a single infarction of the precentral branch of the middle cerebral artery. In the other 2 patients, lesions were due to surgical resection for a meningioma or an arteriovenous malformation (see Table 1). Eight of the patients had lefthemisphere lesions, and 3 had right-hemisphere lesions. The average lesion volume was $39.6 \mathrm{cc}(S D=29.7)$, as estimated by computerized reconstructions of the lesion site using CT or MR scans, and the average time since CVA was 9.7 years $(S D=5.1$; see Table 1$)$. Patients were screened for the absence of prior psychiatric disor- ders, dementia, drug abuse, and head injury. All patients were able to understand and comply with task instructions, although 4 had varying degrees of nonfluent aphasia.

The control participants were the same 10 men and women who participated in Experiment $1 \mathrm{~A}$. Patients and controls did not differ in terms of age $(M=65.6$ years, $S D=12.1$, and $M=65.0$ years, $S D=6.2$, respectively) $[F(1,19)=0.02, p>.8]$ or education $(M=$ 13.8 years, $S D=1.6$, and $M=14.4$ years, $S D=2.3$, respectively) $[F(1,19)=0.44, p>.5]$. All participants reported having normal color vision, except for 1 patient (W.T.), who was therefore excluded from the experiment. All participants were right-handed. Testing occurred at the Veterans Administration Northern California Health Care System (Martinez, CA). All participants signed consent forms prior to participating in the experiment.

Design and Materials. The experiment included two withinsubjects variables, delay $(0,9$, or $20 \mathrm{sec})$ and task condition (nointerference or interference task), and one between-subjects variable, participant group (patient or control). The task condition was manipulated across blocks of trials: On one block, the participants had to perform the interference task; on another block, the participants stared passively at the task display but did not perform the task. Half of the participants in each group performed the interference task in the first block, and half performed it in the second block. Within a block, there were 48 trials, consisting of an equal number of 0-, 9-, and 20-sec delay trials. Practice blocks consisted of 12 trials, 4 trials of each delay.

The task was presented on a 12-in. Apple monitor connected to a Macintosh computer, and the mouse was used to make responses. The color stimuli were generated from the color palette and consisted of 254 possible colors. The color palette was created by continuously modulating the Macintosh "hue" parameter in 254 steps around the palette. These colors were muted and were of approximately equal hue and saturation but were not isoluminant. Color stimuli were presented on the white background of the monitor. The color targets were filled circles, with a diameter subtending $0.6^{\circ}$ of visual angle, and were presented $0.4^{\circ}$ below the central square. The color spectrum used for recognition was a ring (see Figure 2B) with an inner radius of $1.9^{\circ}$ and an outer radius of $3.3^{\circ}$ of visual angle. The presentation format was essentially the same as in Experiments $1 \mathrm{~A}$ and $1 \mathrm{~B}$.

Procedure. The participants were tested individually in a noiseattenuated testing room and were seated approximately $60 \mathrm{~cm}$ from the monitor. For each block of trials, the experimenter first demonstrated how to perform the task on two or three trials. The participants then performed one block of practice and one block of data trials. This procedure was repeated for the second block of trials.

The general procedure was similar to that used in Experiments $1 \mathrm{~A}$ and $\mathrm{IB}$. The participants initiated a trial with a mouse click and were then presented a target stimulus. In this color task, however, the target stimulus was always presented just below the fixation point for 100 msec. Also, rather than a black stimulus, the stimulus was colored, and the participants were asked to remember the color of the stimulus. Half of the trials were performed in conjunction with the digit interference task, which was the same as that used in Experiments $1 \mathrm{~A}$ and $1 \mathrm{~B}$.

To score color working memory performance, each color was assigned a number from 1 to 254 , which corresponded to a rank order of the available colors around the spectrum. The dependent variable was the absolute value of the difference between the assigned number of the response color and that of the actual target color.

\section{Results and Discussion}

Patients versus elderly controls. Responses from the color working memory task were analyzed in a $3 \times 2 \times$ 2 mixed ANOVA, with delay $(0,9$, or $20 \mathrm{sec})$, task con- 


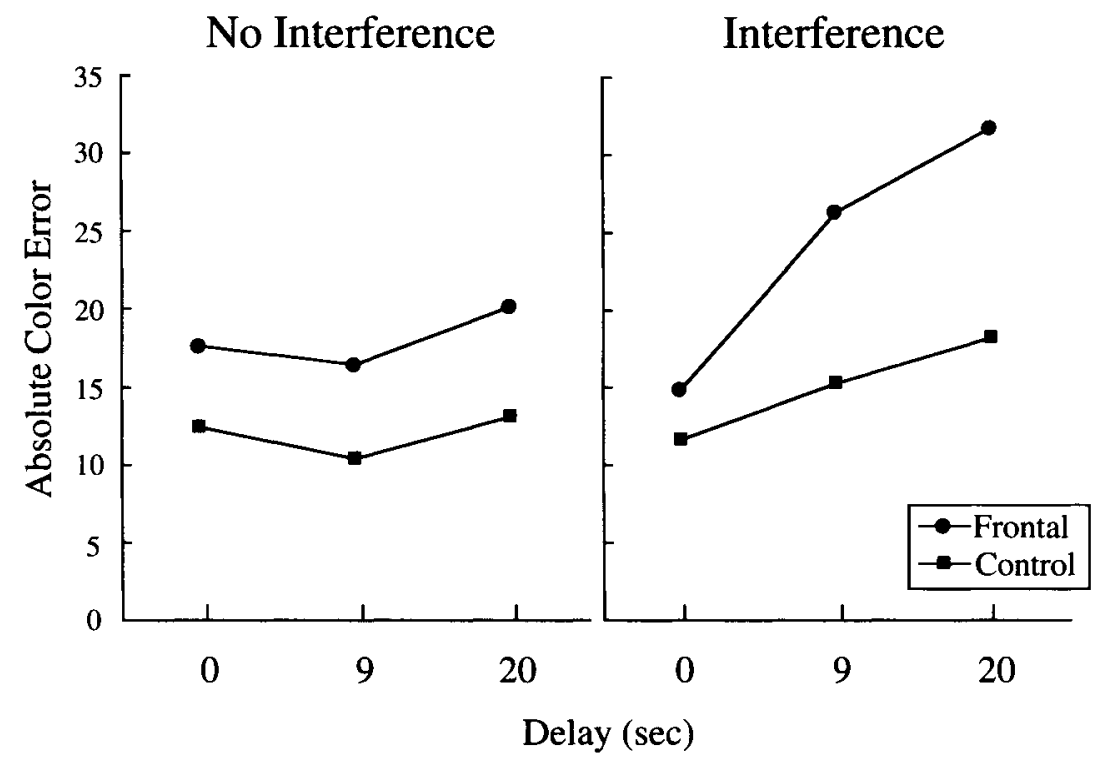

Figure 4. Absolute color error as a function of delay and task condition for frontal patients and controls in Experiment 2.

dition (no-interference or interference task), and group (control or patient) as variables. In a preliminary analysis, there was no effect of block order, and thus this variable is not considered further.

Mean error rates for patients and controls are shown in Figure 4. There was a main effect of group $[F(1,19)=$ $34.31, p<.0001]$, since patients performed worse overall on the color working memory task. There were also main effects of delay $[F(2,38)=17.57, p<.0001]$ and task condition $[F(1,19)=45.12, p<.0001]$. The main effect of delay was due to the fact that overall performance declined at longer delays, and the effect of task condition reflects the fact that performance was worse for all participants in the interference task condition. There was a delay $\times$ task condition interaction $[F(2,38)=12.54, p<$ $.0001]$, since all participants' performance worsened at longer delays in the interference task condition but remained about the same in the no-interference condition (see Figure 4).

Importantly, there were two significant interactions with the group variable: a task $\times$ participant group interaction $[F(1,19)=5.17, p<.05]$ and a delay $\times$ participant group interaction $[F(2,38)=3.64, p<.05]$. The task condition $\times$ participant group interaction reflects the fact that patients were disproportionately affected by the interference task, relative to controls. That is, patients' performance was considerably worse than controls' in the interference task condition only. The delay $\times$ group interaction suggests that the patients were disproportionately affected by delay. On the basis of the data presented in Figure 4, this interaction appears to have been mainly driven by the patients' exceptionally poor performance in the interference condition, since a delay $x$ group interaction was not apparent in the no-interference condition.

Interference task. The participants' performance on the interference task was analyzed across the two delay conditions ( 9 and $20 \mathrm{sec}$ ). These comparisons do not include data from 1 control subject whose data were collected incorrectly due to a programming error. The main effect of group was significant $[F(1,18)=10.52, p<.01]$, since controls exhibited a higher hit rate than patients $(91.7 \%$ vs. $71.8 \%)$. There was no effect of delay, but there was an interaction of group $\times$ delay $[F(1,18)=6.55, p<$ $.05]$. This effect was due to the fact that controls' mean hit rate was slightly lower in the 9-sec delay condition than in the 20 -sec delay condition $(90.9 \%$ vs. $92.4 \%$, respectively), whereas the patients' hit rate was slightly higher in the 9-sec delay condition than in the $20-\mathrm{sec}$ delay condition ( $73.3 \%$ vs. $70.4 \%)$.

Patients made more false alarms than did controls $(M=$ $1.6 \%, S D=1.4 \%$, and $M=0.6 \%, S D=0.6 \%$, respectively) $[F(1,18)=4.70, p<.05]$. False-alarm rates were comparable across the 9 - and 20 -sec delay conditions for both patients and controls.

Separate $d^{\prime}$ scores were calculated for data from the interference task. Patients had an average $d^{\prime}$ of 2.90 , and controls had an average of 4.03 , a statistically significant difference $[F(1,18)=23.17, p<.0001]$. Patients' lower $d^{\prime}$ scores are indicative of impaired performance overall on this interference task. All participants were observed by the experimenter to be focused on the interference task, but the patients were simply less able to accurately respond to targets.

Correlations with lesion volume and chronicity. Correlational analyses were conducted to compare pa- 
tients' performance on the color working memory task with three variables: percentage of Area 46 lesioned, lesion volume, and time since CVA. The performance measure was the average absolute error across all conditions of the experiment. The relationship between lesion volume and performance was significant $(R=.65, p<$ $.05)$. The correlations with percentage of Area 46 affected and lesion chronicity were not significant $(R=.43, p>$ .18 , and $R=.37, p>.25$, respectively).

Summary. Patients with LPFC lesions showed impaired performance on a color working memory task, relative to controls. This impairment in patients was exacerbated by the introduction of an interference task during the delay period. Unlike the findings from the spatial working memory task, color working memory performance suggested that the LPFC patients had disproportionate difficulty in the active maintenance of color information under interference conditions. Hemispheric effects were not assessed due to the small number of right-hemisphere patients in Experiment $2(n=3)$.

\section{GENERAL DISCUSSION}

Patients with LPFC lesions and controls were assessed on a series of working memory tasks. Overall, LPFC patients exhibited impaired performance on both spatial and color working memory tasks, relative to elderly controls. In Experiment 1, LPFC patients exhibited impaired performance on spatial working memory tasks with delays of up to $20 \mathrm{sec}$. That patients were impaired on the spatial task even in the 0 -sec delay condition suggested that a larger deficit in stimulus encoding was the primary deficit and may have masked any working memory deficits. An interference task (monitoring digits) during the delay period affected spatial working memory performance in patients and controls comparably. In Experiment 2, LPFC patients also exhibited impairment on a color working memory task, relative to controls. Unlike in the spatial working memory task in Experiment 1, there was a clear interaction such that patients' performance was disproportionately affected by the addition of an interference task during the delay. Also, patients' and controls' performance was more comparable in the 0 -sec delay condition, with patients showing much poorer performance at longer delays. These results were clearly indicative of a working memory deficit.

A second difference between performance in the spatial and color working memory tasks was observed in the correlations between lesion site and memory performance. For the spatial working memory task, performance was correlated with the extent of damage to Brodmann's Area 46, but not to the overall extent of the lesion. In the color working memory task, performance was not correlated specifically with damage to Area 46 , but it was correlated with the overall extent of damage. The correlational analyses suggest that spatial working memory impairment may be particularly related to damage to Area 46-a finding that corroborates the importance of the homologous region in spatial delayed-response performance in monkeys (Goldman-Rakic, 1987).

In the present study, we did not find any evidence of a hemispheric effect in the spatial working memory task: Patients with right LPFC lesions performed comparably to left LPFC patients. Also, there was no indication that patients performed worse when the target was in their contralesional visual field. These results are similar to at least one human lesion study (Ptito et al., 1995), but they are not consistent with previous animal studies that found evidence of spatially selective regions of PFC or with theories that suggest that spatial and nonspatial working memory are mediated by separate hemispheres. Our working memory tasks, however, were quite complex and involved a number of processes. Even the spatial working memory task probably engaged left hemisphere/verbal functions, because of the digit-monitoring (interference) task during the delay period. Moreover, spatial working memory tasks in human neuroimaging studies have found that brain activation is not specific to the visual half-field and that both left and right hemispheres are recruited, although the right hemisphere more strongly (Smith, Jonides, \& Koeppe, 1996).

Another interesting distinction has been made in animal studies between a more dorsal region of LPFC for spatial working memory and a more ventral region for nonspatial information (e.g., Wilson et al., 1993). Many of the patients in the present study had lesions that encompassed both inferior and more dorsal regions of LPFC, and, therefore, it was difficult to assess this hypothesis. However, data from a subset of our patients with more focal dorsal or ventral lesions (E.B., S.R., O.A., and R.M.) did not support this spatial/nonspatial distinction. A recent review and meta-analysis of human neuroimaging studies also did not find evidence for such a dorsal/ventral distinction for spatial versus nonspatial working memory (D'Esposito et al., 1998). They concluded that, at least in humans, such a distinction may depend on other critical processes (see Petrides et al., 1993).

In addition to deficits in the maintenance of information over brief delays, the present findings suggest that encoding and selection of stimulus information is affected in LPFC patients. The inability of LPFC patients to disengage from the mouse click (to initiate the trial) and to engage in selecting and encoding the target stimulus may have decreased performance at the 0 -sec delay. Indeed, there exist both behavioral (Perret, 1974; Rafal et al., 1996) and electrophysiological (Yamaguchi \& Knight, 1990 ) findings that suggest a role of prefrontal cortex in stimulus selection and filtering. For example, Knight and colleagues (Knight, 1991; Knight, Scabini, \& Woods, 1989; Woods \& Knight, 1986; Yamaguchi \& Knight, 1990 ) studied scalp evoked potentials to sensory stimuli in patients with frontal lobe lesions. In these studies, the amplitude of middle latency evoked potentials, which are presumed to be generated in primary sensory cortices, were potentiated as a result of frontal lobe lesions. Thus, there appeared to be a disinhibition of posterior cortical 
activity as a result of frontal lobe lesions. These findings suggest that prefrontal cortex is involved in the gating of sensory signals. Failure to gate or filter recently active sensory signals could act to impair the ability to select and encode pertinent stimulus information.

Another potential explanation of impaired performance at the 0 -sec delay, is that, although patients were able to respond immediately after the target, it usually took $1-2 \mathrm{sec}$ to move the cursor to the desired location. It is possible that some decay may have occurred within that time, since studies with monkeys have detected a spatial working memory impairment even at a $1.5-\mathrm{sec}$ delay (Goldman-Rakic, 1987).

The present findings, as well as previous research, have shown that prefrontal cortex lesions produce increased susceptibility to interference or distraction (Bartus \& Levere, 1977; Chao \& Knight, 1996; Malmo, 1942; Ptito et al., 1995). Also, evidence from neuroimaging studies supports the role of LPFC in mitigating distraction in divided attention tasks. For example, D'Esposito et al. (1995) reported significant prefrontal activation when participants performed two tasks simultaneously (mental rotation and semantic judgment) but observed no prefrontal activation when they performed either of these tasks alone. In the present study, there was evidence of increased susceptibility to interference in the patients when they were required to monitor digits and maintain color memory. However, the patients were not disproportionately affected by the distracting digit task when they were required to maintain spatial memory. It may be that the ability to monitor digits and color memory depend more critically on shared working memory processes. Perhaps, the digit-monitoring task depended more on phonological rehearsal (i.e., subvocal) processes, and these processes affected the maintenance of color information more than spatial information.

The present study affirms the importance of prefrontal cortex in rather early stages of stimulus processing, such as stimulus selection and encoding, in addition to the active maintenance of information during a delay period. Some theories of prefrontal function have focused on the active maintenance of memories when the physical stimulus is removed (Baddeley, 1986; Fuster, 1989; GoldmanRakic, 1987, 1998), while other theories have emphasized the role of prefrontal cortex in the control and manipulation of memory or response decisions (Duncan, Burgess, \& Emslie, 1995; Owen, Downes, Sahakian, Polkey, \& Robbins, 1990; Owen, Morris, Sahakian, Polkey, \& Robbins, 1996; Shimamura, 1995). Recently, some studies have suggested a multiple-components view in which maintenance and manipulation of working memory are mediated by separate discrete regions of prefrontal cortex (D'Esposito et al., 1998; Petrides et al., 1993). With respect to attentional theories of prefrontal function, Shimamura (1995) has suggested that a gating or filtering problem may extend to the selection of memory and re- sponse decisions. As such, problems in "dynamic filtering" may affect various aspects of information processing, from the registration of sensory signals to the maintenance of information in working memory to the initiation of a response.

\section{REFERENCES}

Awh, E., Jonides, J., Smith, E. E., Schumacher, E. H., Koeppe, R. A., \& KATZ, S. (1996). Dissociation of storage and rehearsal in verbal working memory: Evidence from positron emission tomography. Psychological Science, 7, 25-31.

BADDELEY, A. D. (1986). Working memory. Oxford: Oxford University Press.

Bartus, R. T., \& Levere, T. E. (1977). Frontal decortication in rhesus monkeys: A test of the interference hypothesis. Brain Research, 119 , 233-248.

Blake, M. O., Meyer, D. R., \& Meyer, P. M. (1966). Enforced observation in delayed response learning by frontal monkeys. Journal of Comparative \& Physiological Psychology, 61, 374-379.

ChaO, L. L., \& KNIGHT, R. T. (1996). Human prefrontal lesions increase distractibility to irrelevant sensory inputs. NeuroReport, 6, 45-50.

Cohen, J. D., Perlestein, W. M., Braver, T. S., Nystrom, L. E., Noll, D. C., Jonides, J., \& SmitiI, E. E. (1997). Temporal dynamics of brain activation during a working memory task. Nature, 386, 604608.

D'Esposito, M., Aguirre, G. K., Zarahn, E., Ballard, D., Shin, R. K., \& LEASE, J. (1998). Functional MRI studies of spatial and nonspatial working memory. Cognitive Brain Research, 7, 1-13.

D'Esposito, M., Detre, J. A., Alsop, D. C., Shin, R. K., Atlas, S., \& Grossman, M. (1995). The neural basis of the central executive system of working memory. Nature, 378, 279-281.

DunCAN, J., Burgess, P., \& EMSLIE, H. (1995). Fluid intelligence after frontal lobe lesions. Neuropsychologia, 33, 261-268.

Fiez, J. A., Raife, E. A., Balota, D. A., Schwartz, J. P., Raichle, M. E., \& Petersen, S. E. (1996). A positron emission tomography study of the short-term maintenance of verbal information. Journal of Neuroscience, 16, 808-822.

Freedman, M., \& Oscar-Berman, M. (1986). Bilateral frontal lobe disease and selective delayed response deficits in humans. Behavioral Neuroscience, 100, 337-342.

Funahashi, S., Bruce, C. J., \& Goldman-Rakic, P. S. (1993). Dorsolateral prefrontal lesions and oculomotor delayed-response performance: Evidence for mnemonic "scotomas." Journal of Neuroscience, 13, 1479-1497.

Fuster, J. M. (1989). The prefrontal cortex. New York: Raven.

Fuster, J. M., \& AleXander, G. (1971). Neuron activity related to short-term memory. Science, 173, 652-654.

Goldman, P. S., \& Rosvold, H. E. (1970). Localization of function within the dorsolateral prefrontal cortex of the rhesus monkey. $E x$ perimental Neurology, 27, 291-304.

Goldman-RaKIC, P. S. (1987). Circuitry of primate prefrontal cortex and regulation of behavior by representational memory. In F. Plum (Ed.), Handbook of physiology: Section 1. The nervous system. Vol. 5. Higher functions of the brain. Part I (pp. 373-417). Bethesda, MD: American Physiological Society.

GoldMAN-RAKIC, P. S. (1998). The prefrontal landscape: Implications of functional architecture for understanding human mentation and the central executive. In A. C. Roberts, T. W. Robbins, \& L. Weiskrantz (Eds.), The prefrontal cortex: Executive and cognitive functions (pp. 87-102). New York: Oxford University Press.

JACOBSEN, C. F. (1936). Studies of cerebral functions in primates. Comparative Psychology Monographs, 13, 1-60.

Jonides, J., Smith, E. E., Koeppe, R. A., Awh, E., Minoshima, S., \& Mintun, M. A. (1993). Spatial working memory in humans as revealed by PET. Nature, 363, 623-625.

KNIGHT, R. T. (1991). Evoked potential studies of attention capacity in 
human frontal lobe lesions. In H. Levin, H. Eisenberg, \& A. Benton (Eds.), Frontal lobe function and dysfunction (pp. 139-153). New York: Oxford University Press.

KNight, R. T., Scabini, B., \& Woods, D. L. (1989). Prefrontal cortex gating of auditory transmission in humans. Brain Research, 504, 338342.

MaLmo, R. B. (1942). Interference factors in delayed response in monkeys after removal of frontal lobes. Journal of Neurophysiology, $\mathbf{5}$, 295-308.

McCarthy, G., Blamire, A. M., Puce, A., Nobre, A. C., Bloch, G., Hyder, F., Goldman-Rakic, P S., \& Shulman, R. G. (1994). Functional magnetic resonance imaging of human prefrontal cortex activation during a spatial working memory task. Proceedings of the $\mathrm{Na}$ tional Academy of Sciences, 91, 8690-8694.

McCarthy, G., Puce, A., Constable, R. T., Krystal, J. H., Gore, J. C., \& Goldman-RakiC, P. S. (1996). Activation of human prefrontal cortex during spatial and nonspatial working memory tasks measured by functional MRI. Cerebral Cortex, 6, 600-611.

Miller, E. K., ERICKson, C. A., \& Desimone, R. (1996). Neural mechanisms of visual working memory in prefrontal cortex of the macaque. Journal of Neuroscience, 16, 5154-5167.

Mishkin, M., \& Pribram, K. H. (1956). Analysis of the effects of frontal lesions in monkey: I. Variations of delayed response. Journal of Comparative \& Physiological Psychology, 49, 36-40.

Owen, A. M., Downes, J. J., Sahakian, B. J., Polkey, C. E., \& RobBINS, T. W. (1990). Planning and spatial working memory following frontal lobe lesions in man. Neuropsychologia, 28, 1021-1034.

Owen, A. M., Morris, R. G., Sahakian, B. J., Polkey, C. E., \& RobBINS, T. W. (1996). Double dissociations of memory and executive functions in working memory tasks following frontal lobe excisions, temporal lobe excisions or amygdalo-hippocampectomy in man. Brain, 119, 1597-1615.

Perret, E. (1974). The left frontal lobe of man and the suppression of habitual responses in verbal categorical behavior. Neuropsychologia, 12,323-330.

Petrides, M. (1998). Specialized systems for the processing of mnemonic information within the primate frontal cortex. In A. C. Roberts, T. W. Robbins, et al. (Eds.), The prefrontal cortex: Execu- tive and cognitive functions (pp. 103-116). New York: Oxford University Press.

Petrides, M., Alivisatos, B., Evans, A. C., \& Meyer, E. (1993). Dissociation of human mid-dorsolateral from posterior dorsolateral frontal cortex in memory processing. Proceedings of the National Academy of Sciences, 90, 873-877.

Ptito, A., Crane, J., Leonard, G., Amsel, R., \& Caramanos, $Z$. (1995). Visual-spatial localization by patients with frontal-lobe lesions invading or sparing area 46. NeuroReport, 6, 1781-1784.

Rafal, R. D., Gershberg, F B., Egly, R., IVry, R. B., Kingstone, A. \& Ro, T. (1996). Response channel activation and the lateral prefrontal cortex. Neuropsychologia, 34, 1197-1202.

Rainer, G., ASAAD, W. F., \& Miller, E. K. (1998). Selective representation of relevant information by neurons in the primate prefrontal cortex. Nature, 393, 577-579.

RaO, S. C., Rainer, G., \& Miller, E. K. (1997). Integration of what and where in the primate prefrontal cortex. Science, 276, 821-824.

Shimamura, A. P. (1995). Memory and frontal lobe function. In M. S Gazzaniga (Ed.), The cognitive neurosciences (pp. 803-813). Cambridge, MA: MIT Press.

SMITH, E., \& JoNidEs, J. (1999). Storage and executive processes in the frontal lobes. Science, 283, 1657-1661.

SMith, E. E., Jonides, J., \& KoEPPE, R. A. (1996). Dissociating verbal and spatial working memory using PET. Cerebral Cortex, 6, 11-20.

Smith, E. E., Jonides, J., Koeppe, R. A., Awh, E., Schumacher, E. H., \& Minoshima, S. (1995). Spatial versus object working memory: PET investigations. Journal of Cognitive Neuroscience, 7, 337-358.

Wilson, F. A., Scalaidhe, S. P., \& Goldman-Rakic, P. S. (1993). Dissociation of object and spatial processing domains in primate prefrontal cortex. Science, 260, 1955-1958.

WoODS, D. L., \& KNIGHT, R. T. (1986). Electrophysiologic evidence of increased distractibility after dorsolateral prefrontal lesions. Neurol$o g y, 36,212-216$.

YamaguChI, S., \& KNIGHT, R. T. (1990). Gating of somatosensory input by human prefrontal cortex. Brain Research, 521, 281-288.

(Manuscript received September 23, 1999; revision accepted for publication April 6, 2000.) 